\title{
10-Gbps duobinary-4-PAM for High-Performance Access Networks
}

\section{Suhr, Lau Frejstrup; Vegas Olmos, Juan José; Tafur Monroy, Idelfonso}

\section{Published in:}

Proceedings of Asia Communications and Photonics Conference 2014.

Link to article, DOI:

10.1364/ACPC.2014.ATh3A.161

Publication date:

2014

Link back to DTU Orbit

Citation (APA):

Suhr, L. F., Vegas Olmos, J. J., \& Tafur Monroy, I. (2014). 10-Gbps duobinary-4-PAM for High-Performance Access Networks. In Proceedings of Asia Communications and Photonics Conference 2014. Optical Society of America. https://doi.org/10.1364/ACPC.2014.ATh3A.161

\section{General rights}

Copyright and moral rights for the publications made accessible in the public portal are retained by the authors and/or other copyright owners and it is a condition of accessing publications that users recognise and abide by the legal requirements associated with these rights.

- Users may download and print one copy of any publication from the public portal for the purpose of private study or research.

- You may not further distribute the material or use it for any profit-making activity or commercial gain

- You may freely distribute the URL identifying the publication in the public portal

If you believe that this document breaches copyright please contact us providing details, and we will remove access to the work immediately and investigate your claim 


\title{
10-Gbps duobinary-4-PAM for High-Performance Access Networks
}

\author{
L. F. Suhr*, J.J. Vegas Olmos, and I. Tafur Monroy \\ Technical University of Denmark, Department of Photonics Engineering, Ørsted Plads 343, Kgs. Lyngby, Denmark \\ *s103213@student.dtu.dk
}

\begin{abstract}
This paper reports on an experimental demonstration of a seven level duobinary-4PAM signal operating at $10.16 \mathrm{Gbps}$, implemented analogically and featuring direct detection at the receiver side.
\end{abstract}

\section{Introduction}

The explosion of internet applications and media delivery over IP has fuelled the research for faster broadband connections in access networks. Fiber-based access networks are widely regarded as the main technological direction that can efficiently provide scalable bandwidth; copper-based and wireless-based solutions compete with fiber-bases solutions on the last few meters, yet fiber-based optical access networks are indeed bond to become the main skeleton of high-performance access networks. An issue under heavy study in this field is whether to put forward multilevel modulation formats. Multilevel or advanced modulation formats enable to increase the available bitrate of a system while keeping the bandwidth of the required photonic and electronic components and the deployed optical distribution network unchanged. Since optical access networks are extremely cost sensitive, and electronic/optic systems with bandwidth beyond $10 \mathrm{GHz}$ become more complex, the introduction of multilevel modulation formats seem to be a matter of timing.

Proposed solutions include Orthogonal Frequency-Division Multiplexing (OFDM), in where spatial and frequency bit allocation schemes can be implemented, adding a new layer of reconfigurability [1]. Carrierless Amplitude Phase (CAP) [2] provides high spectral efficiency with simplified transmitter and receivers based on electrical passband filters. These two solutions, although relaxed in terms of electronic circuitry, placed some pressure on the optical side, as high extinction ratio or good linearity. Multilevel modulation formats based on well-known On-Off Keying (OOK) such as pulse-amplitude modulation (PAM)-4 or PAM- 8 are also envisioned as possible candidates to increase the efficiency of the modulation format in access networks [3].

In this paper, we propose and experimentally demonstrate, the reduce further the bandwidth requirements on PAM-4 by using polybinary signaling [4]. A PAM-4 with an effective bitrate of $10 \mathrm{Gbps}$ is converted into a polybinary signal, reducing the necessary electrical bandwidth. The complexity at the transmitter and receiver is low, enabling the usage of GPON class optics for $10 \mathrm{Gbps}$ optical access networks.

\section{Duobinary 4-PAM}

Partial response signaling was first proposed to increase the spectral efficiency by exploiting Intersymbol Interference (ISI) Strong filtering of an on-off keying signal normally generates a polybinary signal. Strong filtering of the OOK induces ISI by removing the upper part of the spectra, effectively reducing the given bandwidth. Depending on the filter bandwidth, duobinary signals are obtained, or in the general case, M-levels signal streams. Lender, in 1964, predicted that multilevel signals can be also used to generate polybinary signals after strong filtering [5] Therefore, strong filtering can further boost the already increased spectral efficiency. In this work, we employed a 4-PAM signal as seed for a duobinary filter, effectively obtaining a duobinary-4- PAM 7-level signal. Because the generation method introduces correlation between adjacent bits, meaning that the current bit is also defined by the values of the k preceding bits, codification at the transmitter side is necessary in order to avoid error propagation at the receiver side. Considering $a_{k}$ the original bit sequence, $b_{k}$ a precoded 4-PAM sequence, and $c_{k}$ the seven-level generated signal, it is possible to recover the original 4-PAM sequence from independent decisions on $c_{k}$, provided the following relationships are used:

$$
b_{k}=a_{k}-b_{k-1} \bmod 4
$$




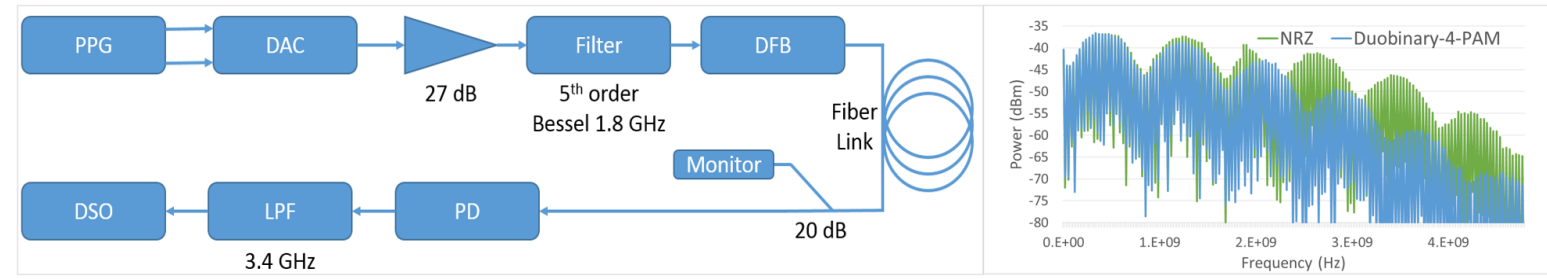

Fig. 1. On the left is the setup used for the experiment. On the right side a comparison of the 5.08

GBaud duobinary-4-PAM spectrum is compared to a 5.08 GBaud NRZ spectrum

$$
\begin{gathered}
c_{k}=b_{k}+b_{k-1} \\
a_{k}+c_{k} \bmod 4
\end{gathered}
$$

The simplicity of the transmitter is outstanding; digital coding is a simple bit-to-bit operation and only analog filtering is needed after the 4-PAM generation. Analog solutions are already commercially available at low cost. The receiver side is equally frugal, as a simple sample point approach is used, avoiding the need for hungry digital signal processing (DSP) methods. The only necessary DSP processing consists in a mod4 operation.

\section{Experimental setup}

The experimental setup used to generate, transmit and receive the duobinary-4-PAM signal is shown in Fig. 1. One 5.08 Gbps Pseudo Random Bit Sequence (PRBS) and one logically inverted 5.08 Gbps PRBS was generated by a single Pulse Pattern Generator (PPG). Both streams were then multiplexed with a Digital-to-Analog Converter (DAC). After amplification the now 4-PAM signal, was filtered with a $1.8 \mathrm{GHz}$ Bessel filter in order to generate the duobinary4-PAM signal. The duobianry-4-PAM signal was then used to drive a Distributed Feedback laser (DFB) operating at $1550 \mathrm{~nm}$. The DFB was a commercial distributed feedback laser with a $10 \mathrm{GHz}$ bandwidth with a bias current of $60 \mathrm{~mA}$. After transmission over various Single-Mode Fibers (SMFs) the signal was detected by a $10 \mathrm{GHz}$ Photodiode (PD). Before reception by a $40 \mathrm{Gsa}$ Digital Storage Oscilloscope (DSO), the signal was filtered by a $3.4 \mathrm{GHz}$ Low-Pass Filter (LPF) to remove out of band noise. Off-line processing was implemented in MATLAB with a single decision point in time per bit.

\section{Results}

Fig. 2 shows the measured Bit Error Rate (BER) for 10, 20 and $40 \mathrm{~km}$ Standard Single-Mode Fiber (SSMF), and 5, 10, 20 and $40 \mathrm{~km}$ for Dispersion Shifted Fiber (DSF) and Non-Zero Dispersion Shifted Fiber (NZDSF). The needed BER

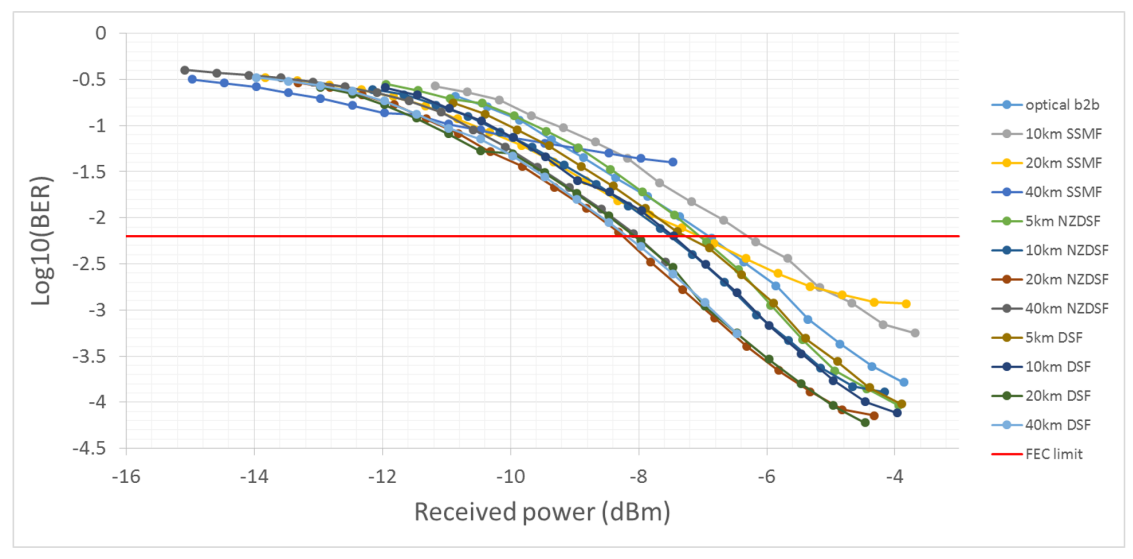

Fig. 2. The BER for the experiment 


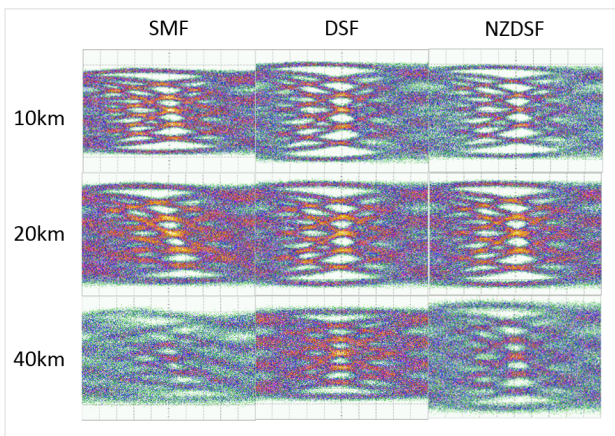

Fig. 3. The eye-diagrams for the 10, 20 and $40 \mathrm{~km}$ transmission lengths over different types of fibers. Dispersion is noticeable in the SMF, as the eye diagram is skewed

for error free recovery through \%7-overhead Forward Error Correction (FEC) is $2.2 \times 10^{2.2}$. Some of the measured points in the BER from -2.5 towards -0.5 were affected by scaling of the DSO, therefore an off-set penalty has been added to these points for all the measurements to form a consistent BER curve. The receiver sensitivity for this BER is between -8 and $-6 \mathrm{dBm}$ all fiber types except $40 \mathrm{~km}$ SSMF which was not recoverable.

In the experiment only a single sampling point in time was used per bit. This means that dispersion induced skewing of the eye caused the $40 \mathrm{~km} \mathrm{SSMF}$ to be unrecoverable.

\section{Conclusion}

This paper presents a seven-level duobinary-4-PAM signal that has been successfully generated and transmitted over a $40 \mathrm{~km}$ optical link. The total bitrate obtained is $10.14 \mathrm{Gbps}$ using only a single wavelength and direct detection. The transmitter relies on a simple setup, consisting of a PPG with two outsput ports, a DAC and a $1.8 \mathrm{GHz}$ low pass filter to generate the duobinary signal, which means the implementation is extremely simple. The receiver side is based on direct detection with a simple Digital Signal Processing (DSP) recovery scheme. The receiver sensitivity is reduced because of the extra generated levels compared to a standard 4-PAM signal, but the reduced spectral usage is sufficient to compensate for this penalty in optical access networks, or eventually, in short range access networks and data center interconnects.

\section{Acknowledgements}

The authors would like to thank the European Commission for partly funding this research through the Marie Curie FENDOI project.

\section{References}

1. E. Giacoumidis, A. Kavatzikidis, A. Tsokanos, J. M. Tang, and I. Tomkos "Adaptive Loading Algorithms for IMDD Optical OFDM PON Systems Using Directly Modulated Lasers" IEEE Journal of Optical Communications and Networking 4 (10),769-778 (2012)

2. M. B. Othman, X. Zhang, J. B. Jensen, and I. T. Monroy "Using CAP Dimensionality for Service and User Allocation for Optical Access Networks" Asia Communications and Photonics Conference, paper AS3C.5. (2012)

3. N. Cheng, X. Yan, N. Chand, and F. Effenberger " $10 \mathrm{~Gb} / \mathrm{s}$ Upstream Transmission in TWDM PON Using Duobinary and PAM-4 Modulations with Directly Modulated Tunable DBR Laser" Asia Communications and Photonics Conference, paper ATh3E.4. (2013)

4. J. J. Vegas Olmos, Lau Frejstrup Suhr, Bomin Li, and I. Tafur Monroy "Five-level polybinary signaling for 10 Gbps data transmission systems" Opt. Express 21, 20417-20422 (2013)

5. A. Lender "Correlative digital communication techniques". IEEE trans. commun. Technol. 12 (4), 128-135 (1964) 